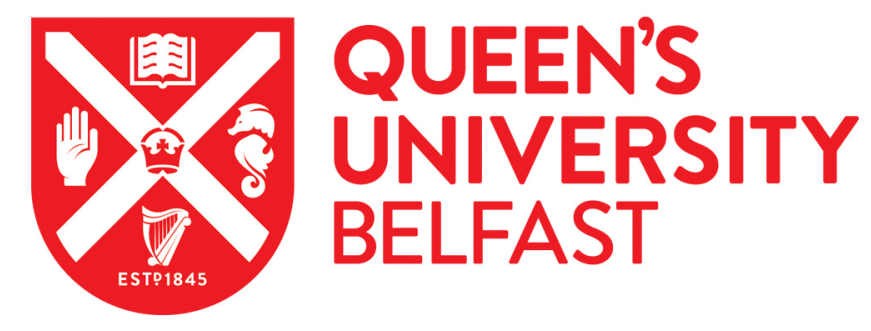

\title{
Dietary fat intakes in Irish children - changes between 2005 and 2019
}

O'Connor, A., Buffini, M., Nugent, A., Kehoe, L., Flynn, A., Walton, J., Kearney, J., \& McNulty, B. (2020). Dietary fat intakes in Irish children - changes between 2005 and 2019. Public Health Nutrition, 1-21.

https://doi.org/10.1017/S1368980020004255

Published in:

Public Health Nutrition

Document Version:

Peer reviewed version

Queen's University Belfast - Research Portal:

Link to publication record in Queen's University Belfast Research Portal

Publisher rights

Copyright 2020 Cambridge University Press. This work is made available online in accordance with the publisher's policies. Please refer to any applicable terms of use of the publisher.

\section{General rights}

Copyright for the publications made accessible via the Queen's University Belfast Research Portal is retained by the author(s) and / or other copyright owners and it is a condition of accessing these publications that users recognise and abide by the legal requirements associated with these rights.

Take down policy

The Research Portal is Queen's institutional repository that provides access to Queen's research output. Every effort has been made to ensure that content in the Research Portal does not infringe any person's rights, or applicable UK laws. If you discover content in the Research Portal that you believe breaches copyright or violates any law, please contact openaccess@qub.ac.uk. 


\section{Dietary fat intakes in Irish children - changes between 2005 and 2019}

Aileen O’Connor ${ }^{1}$, Maria Buffini ${ }^{1}$, Anne Nugent ${ }^{1,2}$ Laura Kehoe $^{3}$, Albert Flynn ${ }^{3}$, Janette Walton ${ }^{4}$, John Kearney ${ }^{5}$ and Breige McNulty ${ }^{1}$

${ }^{1}$ Institute of Food and Health, University College Dublin, Belfield, Dublin 4, Ireland; ${ }^{2}$ Institute for Global Food Security, Queens University Belfast, Northern Ireland; ${ }^{3}$ School of Food and Nutritional Sciences, University College Cork, Cork, Ireland; ${ }^{4}$ Department of Biological Sciences, Cork Institute of Technology, Cork, Ireland; ${ }^{5}$ School of Biological and Health Sciences, Technological University Dublin, Dublin, Ireland.

Corresponding author: Dr. Breige McNulty

School of Agriculture and Food Science,

Science Centre - South,

University College Dublin,

Belfield,

Dublin 4

Email address: breige.mcnulty@ucd.ie

Phone number: 017162812

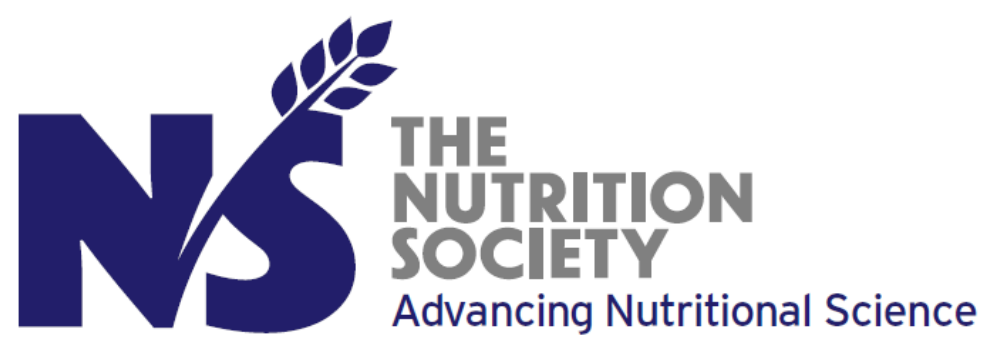

This is an Accepted Manuscript for Public Health Nutrition as part of the Cambridge Coronavirus Collection. This peer-reviewed article has been accepted for publication but not yet copyedited or typeset, and so may be subject to change during the production process. The article is considered published and may be cited using its DOI 10.1017/S1368980020004255

Public Health Nutrition is published by Cambridge University Press on behalf of The Nutrition Society 
Short title: Dietary fat intakes in Irish children - changes between 2005 and 2019

Acknowledgements: The authors gratefully thank all participants who took part in this study and all IUNA team members and colleagues who contributed to survey data collection and entry.

Financial Support: This study was funded by the Irish Department of Agriculture, Food and the Marine (DAFM) under the 2015 Food Institutional Research Measure (FIRM) awards (grant no. 15/F/673).

\section{Conflict of Interest: None.}

Authorship: A.O'C. and B.M.N. analysed and interpreted the data, and wrote the manuscript. M.B. and L.K. prepared the data for analysis. A.N., A.F., J.W., J.K. and B.M.N. contributed to survey design and data collection. J.W. and B.M.N. were principal investigators for NCFS II. All authors approved the final version of the draft before publication.

Ethical Standards Disclosure: This study was conducted according to the guidelines laid down in the Declaration of Helsinki and all procedures involving research study participants were approved by the University College Cork Clinical Research Ethics Committee of the Cork Teaching Hospitals and the Human Ethics Research Committee of University College Dublin [ECM 4 (aa 07/02/2017)]. Written informed consent was obtained from all participants. 


\section{Abstract}

Objective To examine current dietary fat intakes and compliance in Irish children and to examine changes in intakes from 2005 to 2019.

Design Analyses were based on data from the Irish National Children's Food Survey (NCFS) and the National Children's Food Survey II (NCFS II), two cross-sectional studies that collected detailed food and beverage intake data through 7-day and 4-day weighed food diaries, respectively.

Setting NCFS and NCFS II, Republic of Ireland.

Subjects A nationally representative sample of 594 (NCFS) and 600 (NCFS II) children aged 5 12 years. Current intakes from the NCFS II were compared with those previously reported in the NCFS (www.iuna.net).

Results Current intakes of total fat, saturated fatty acids (SFA), monounsaturated fatty acids (MUFA), polyunsaturated fatty acids (PUFA) and trans fat as a percentage of total energy (\% TE) are 33.3, 14.0, 13.6, 5.6 and $0.5 \%$, respectively. Total fat, SFA and trans fat intakes since 2005 remained largely stable over time with all displaying minor decreases of $<1 \%$. Adherence to SFA recommendations remain inadequate, with only $7 \%$ of the population complying. Insufficient compliance with PUFA (71\%) and eicosapentaenoic acid (EPA) and docosahexaenoic acid (DHA; $16 \%)$ recommendations was also noted.

Conclusion Children in Ireland continue to meet the total fat and trans fat target goals. Adherence to MUFA and PUFA recommendations have also significantly improved. However, deviations for some fats remain, in particular SFA. These findings are useful for the development of dietary strategies to improve compliance with current recommendations.

Keywords: Dietary fat: Fatty acid intakes: SFA: PUFA: Children 


\section{Introduction}

Dietary fat is an essential macronutrient in our diet which plays an important role within the body. It acts as an energy substrate, facilitates the absorption of fat-soluble vitamins, is a vital component of cell membranes, and provides protection and insulation of internal organs ${ }^{(1,2)}$. Nevertheless, imbalances in the amount and types of dietary fat consumed have been associated with an increased risk of chronic diseases such as cardiovascular disease (CVD), type 2 diabetes mellitus (T2DM) and some cancers $^{(3)}$. Although presented later in life, many of these chronic diseases stem from prolonged unhealthy dietary behaviours which may have developed in childhood ${ }^{(4)}$.

The evidence surrounding dietary fat and its association with chronic disease risk is widely recognised and as such, dietary fat guidelines have been established by public health organisations to aid public health campaigns in disease prevention ${ }^{(5-7)}$. However, dietary recommendations specific to children are not so clear. The variation in cut-offs for dietary fat recommendations between countries creates a challenge when trying to assess and compare global dietary fat intakes and compliance in children. The Food and Agriculture Organisation of the United Nations (FAO) and World Health Organisation (WHO) recommend that total fat intakes should be between 25 - 35 $\%$ of total energy (\% TE) intake for children from 2 years of age onwards ${ }^{(5)}$. They also recommend that SFA and trans fat should be less than $8 \%$ and $1 \%$ TE, respectively, whereas PUFA should be more than $11 \%$ TE. While the European Food Safety Authority (EFSA) have set a similar range for total fat intakes in children $(20-35 \%)$, they suggest that intake of SFA and trans fat should be as low as possible ${ }^{(6)}$. In addition, they provide no recommendation for total PUFA intakes but they have set a combined recommendation of $250 \mathrm{mg} /$ day for omega-3 $(n-3)$ fatty acids, EPA and $\mathrm{DHA}^{(6)}$.

Even though differing guidelines are widely used, many studies have shown that children rarely adhere to recommendations in terms of dietary fat. Harika et al. published a comprehensive review comparing dietary fat intakes in children and adolescents across thirty countries worldwide, revealing that of the countries surveyed, 90,93 and $70 \%$ did not meet the recommendations for total fat, SFA and PUFA, respectively ${ }^{(8)}$. These compliance rates are similar to those previously reported in Irish children in 2005, with greater compliance noted for total fat (88\%), whereas SFA and PUFA adherence were low, at 6 and $47 \%$, respectively ${ }^{(9)}$.

Such deviations have led to a number of public health campaigns and government-industry partnerships to help improve consumers' dietary fat profile ${ }^{(10,11)}$. For example, reformulation approaches have been carried out to reduce trans fat intakes in the Irish population ${ }^{(12)}$. Since it is unknown whether some of these past initiatives have successfully influenced children's fat 
Accepted manuscript

consumption, it is essential to examine dietary intakes to assess compliance with current dietary guidelines. This will help to identify areas for improvement and subsequently develop focused interventions for those at high risk of developing poor dietary habits ${ }^{(13)}$. Therefore, the aims of this study were to firstly examine current intakes of total fat and fatty acid constituents; secondly to measure compliance with recommendations; and lastly to compare with previous data in order to examine changes in dietary fat intakes over time.

\section{Methods}

\section{Study design and populations}

This analysis is based on data from two cross-sectional national nutrition surveys which examined the habitual food and beverage intake of Irish children aged 5-12 years residing in the Republic of Ireland. The NCFS (2005) and the NCFS II (2019) are comprised of data from 594 (293 boys, 301 girls) and 600 (300 boys, 300 girls) children, respectively ${ }^{(14,15)}$. Recruitment was carried out for the NCFS between March 2003 and March 2004 and for the NCFS II between April 2017 and May 2018. The selection and recruitment process were based on the relevant national population census data $^{(16,17)}$ and participants were recruited from primary schools drawn from the Department of Education and Skills' database ${ }^{(18)}$. Pupils in the schools were randomly selected to be contacted about the surveys. The overall response rates for the NCFS and NCFS II were 63 and $65 \%$, respectively. The rates refer to the percentage of respondents who completed the study upon invitation. There were no exclusion criteria aside from being a sibling to another participant. Analysis of the demographic profile of participants of both surveys demonstrated a representative sample of Irish children with respect to age, gender and geographical location ${ }^{(16,17,19)}$ (Supplementary Table 1). The NCFS was representative of social class, however, the NCFS II sample contained a higher proportion of children of professional workers and a lower proportion of children of semi-skilled and unskilled workers than the national population. Therefore, statistical weighting was applied to all data in the NCFS II to account for these social class differences.

\section{Data collection}

A consecutive 7-day (NCFS) and 4-day (NCFS II) weighed food diary was used to collect food and beverage intake data. Data collection protocol was identical across both surveys, with the 4-day food diary requiring the inclusion of at least one weekend day in order to account for differences in children's eating habits between weekdays and weekends. Participants were visited by a researcher in their home on approximately three occasions during the recording period. Training was given during the initial visit to ensure accuracy of the food records. They were provided with a weighing scales and asked to record detailed information regarding the amount and types of all food and 
Accepted manuscript

beverage intake, including nutritional supplements consumed. The parents and/or guardians typically recorded the food and beverages consumed on behalf of their child. Although, some of the older children recorded their own consumption with assistance from their parents and/or guardians. A food quantification protocol was established by the Irish Universities Nutrition Alliance (IUNA) and adapted for both the NCFS and NCFS II ${ }^{(20)}$. Information such as cooking methods, brand names of foods, recipe details, eating locations and participant definitions of eating occasions, was recorded. Food packaging was also collected to provide additional information of the foods consumed. This level of detail meant that most meals consumed outside of the home could be traced back to the supplier for further information i.e. ingredients, nutritional information and food weight. For unweighted and non-branded foods, a food atlas was utilised to estimate portions of the food consumed. Further details about this protocol can be found on www.iuna.net. The remaining visits were to review the food diary to ensure completion of the 7-day or 4-day food diaries, respectively, and to check for overall survey completeness

Food intake data in the NCFS were analysed using WISP ${ }^{\odot}$ (Tinuviel Software, Anglesey, UK). WISP $^{\odot}$ contains data from McCance and Widdowson's The Composition of Foods, fifth $^{(21)}$ and $\operatorname{sixth}^{(22)}$ editions plus all nine supplemental volumes ${ }^{(23-31)}$ to generate nutrient intake data. In the NCFS II, food intake data were analysed using Nutritics (Nutritics, Dublin, Ireland) which contains data from McCance and Widdowson's The Composition of Foods, sixth ${ }^{(22)}$ and seventh ${ }^{(32)}$ editions. Food composition databases were generated from each survey, listing each individual food item consumed by participants. Each food item was listed with its corresponding nutrient composition. Modifications were made to the food composition database to include recipes of composite dishes, nutritional supplements, generic Irish foods that were commonly consumed, reformulated foods and new foods on the market.

\section{Estimation of fatty acid composition}

Updates were required for the fatty acid of certain foods contained in the NCFS and NCFS II food intake databases, due to outdated concentrations of certain fatty acids composition (total fat, SFA, MUFA, PUFA, trans fat, omega 6 (n-6), n-3, alpha-linolenic acid (ALA), EPA and DHA). The databases were updated by means of a comprehensive methodology providing reliable estimates of dietary intakes of the fatty acids. A similar protocol was utilised in previous Irish national surveys ${ }^{(33)}$. An SPSS database was created containing all foods consumed, including recipes. Each food was assigned a unique food code. All food codes, including recipes, were examined and a fatty acid concentration was assigned to each. A number of data sources were used to update the concentrations such as current published food composition tables (56.8\%), published papers (1.2 $\%)$ and brand information $(0.8 \%)^{(22,32-36)}$. 


\section{Calculating fatty acid intakes in Irish children}

Total fat, SFA, MUFA, PUFA, $n-6, n-3$, EPA, DHA and trans fat values [grams (g)/100g] were estimated in 1945 foods and recipes for NCFS (2005) and 2046 foods and recipes for NCFS II (2019). ALA values were not available for NCFS and therefore, were only estimated for NCFS II. All estimated entries were rechecked by the researcher and, subsequently, a random selection was rechecked by another researcher to reduce the chance of error. Each fatty acid concentration was converted from $\mathrm{g} / 100 \mathrm{~g}$ of food to the actual amount of fatty acid consumed per day (g/day). Usual intakes of nutrients were estimated using the validated NCI method ${ }^{(37)}$ with SAS Enterprise Guide(C software, version 7.1 (www.riskfactor.cancer.gov/diet/usualintakes/macro.html).

\section{Statistical analysis}

Statistical analyses were conducted using SPSS $^{\circledR}$ V24.0 for Windows ${ }^{\mathrm{TM}}$ (SPSS Inc. Chicago, IL, USA). Descriptive statistics including mean and standard deviation were calculated in both surveys for daily total fat, SFA, MUFA, PUFA, $n-6, n-3$, trans fat, ALA, EPA and DHA intakes (g/day and $\% \mathrm{TE})$ for the total population and by gender and age group. Independent sample $t$-tests were performed to compare fatty acid intakes between groups such as survey, gender and age. Compliance with $\mathrm{UK}^{(7,38)}$ and $\operatorname{EFSA}^{(6)}$ dietary fat intake recommendations was assessed using the approach described by Wearne and Day ${ }^{(39)}$. Each food was aggregated into one of 26 food groups, based either on its predominant fat profile or associated food-based dietary guidelines ${ }^{(40,41)}$ (Supplementary Table 2). The percentage contribution of each food group to total fat and fatty acid constituents was then calculated. The Bonferroni correction method for multiple comparisons was utilised and significance for all statistical analyses was classified as $P \leq 0.05$.

\section{Results}

\section{Intakes of dietary fat}

Table 1 presents the mean intakes of total fat and constituent fatty acids (g/day and \% TE) from the NCFS II in 2019. Intakes of total fat, SFA, MUFA and trans fat (\% TE) in the total population were 33.3, 14.0, 13.6 and $0.5 \%$, respectively. The \% TE from PUFA was $5.6 \%$, of which $3.6 \%$ was contributed by $n-6$ and $0.7 \%$ by $n-3$. Within $n-3$ fatty acids, ALA, EPA and DHA were $0.6,0.03$ and $0.04 \%$ TE, respectively. Significant differences between gender and age group were also identified across all fatty acids in g/day and \% TE with higher intakes of all fats (g/day) being consumed by the older cohort $(9-12$ years) and by boys of all ages $(P<0.001)$.

Comparisons between intakes of total fat and constituent fatty acids (g/day and \% TE) in the NCFS (2005) and NCFS II (2019) are displayed in Table 2. Overall, no significant changes were apparent 
Accepted manuscript

for intakes of total fat, which remained similar at 34 and $33 \%$ TE between 2005 and 2019, respectively. Intakes of SFA and trans fat decreased slightly from 14.5 to $14.0 \%$ and 0.53 to 0.51 $\%$ TE, respectively, whereas MUFA, PUFA, $n-6, n-3$, EPA and DHA presented significant increases of 2.1, 0.6, 0.5, 0.1, 0.02 and $0.02 \% \mathrm{TE}$, respectively. Similar trends were observed across gender.

\section{Percentage contribution of food groups to dietary fat}

The percentage contribution of food groups to dietary fat is presented in Tables 3a and b. In 2019, 'meat products', 'biscuits cakes, pastries and buns' and 'whole milk' were among the top sources of total fat, SFA and MUFA, contributing overall 31.5, 27.9, and $27.3 \%$, respectively. Whilst similar in 2005, these collective contributions from the food groups were slightly higher at 38.0, 32.3, and $31.3 \%$, respectively (Table 3a). The top contributors to PUFA intake in both 2005 and 2019 were 'breads and rolls' (10.9\%) and 'meat products' (9.8\%). Current major food sources of EPA and DHA are 'fish, fish products and fish dishes' (25.3\%), 'fresh meat' (19.3\%) and 'whole milk' $(11.8 \%)$, which has remained consistent since 2005 (Table 3b). Nutritional supplements featured as a source of EPA and DHA, however, they did not make a substantial contribution to intakes (1.9 $\%)$. Primary sources of trans fat intakes were 'meat dishes', 'whole milk' and 'cheeses' in 2005 and 2019 with overall contributions from these food sources increasing from 33.1 to $38.7 \%$ over time. 'Meat products' $(10.9 \%)$ were the greatest contributing foods to ALA intakes in 2019 , as well as 'spreading fats and oils' (10.1\%). Of note, significant reductions in the contribution of dairy products to fatty acids are observed from 2005 to 2019, particularly for 'whole milk', 'low-fat spreads' and 'ice-cream and creams'. Despite these reductions, 'whole milk' still remains one of the top contributors across a number of the fatty acids examined, contributing from 6.9 to $15.5 \%$ TE to total fat, SFA, MUFA, EPA, DHA and trans fat intakes. In contrast, 'low fat, skimmed and fortified milks', 'cheeses' and 'butter' presented significant increases in their contributions, ranging from 0.1 to $14.4 \%$. Furthermore, the contribution of 'biscuits, cakes, pastries and buns' also significantly increased across all fatty acids over time.

\section{The percentage of Irish children adhering to dietary fat recommendations at a population level}

The proportion of children adhering to dietary fat recommendations (\% TE) for each fatty acid as a percentage of the total population is illustrated in Figure 1. In 2005, a high level of population compliance with the recommendations for total fat (100\%) and trans fat (100\%) was observed, which continued in 2019. Compliance with MUFA recommendations has shown improvements from 81 to $100 \%$. SFA adherence in 2005 was low at $4 \%$ showing only a slight improvement at 7 $\%$. Although the level has improved, the current rate still remains low at $7 \%$ in 2019 . The 
proportion of children meeting PUFA recommendations was $71 \%$ in 2019 which is an increase of $36 \%$ since 2005. Adherence to EPA and DHA recommendations in the overall population increased from 2 to $16 \%$ between 2005 and 2019. When stratified by gender, compliance across all fatty acids examined was similar to that reported in the total population.

\section{Discussion}

Over the last 14 years, improvements to the overall dietary fat profile in Irish children have been observed. The current findings demonstrate that Irish children continue to achieve total fat and trans fat recommendations (100\%), while adherence to MUFA recommendations has successfully improved to $100 \%$. However, despite these improvements, deviations from the recommendations for SFA, PUFA, and EPA and DHA remain with only 7, 71 and $16 \%$ of the population adhering to these recommendations, respectively.

Changes in the dietary fat intakes of Irish children in the current study are in line with those observed in other European countries ${ }^{(42,43)}$. In a cross-sectional study of German children, dietary fat intakes examined over a ten year period noted a slight decrease in total fat and SFA, decreasing from 35 to $34 \%$ and from 16 to $15 \%$, respectively, whilst MUFA and PUFA intakes remained stable at 14 and $5 \%$, respectively ${ }^{(43)}$. However, compliance with SFA and PUFA recommendations was extremely low ( 3 and $8 \%$, respectively), similar to the findings in the current analysis. In contrast, temporal trend analysis carried out in a cohort of Chinese children observed dietary fat intakes steadily increased between the years 1991 and 2009, as well as the proportion of energy from fat ${ }^{(44)}$. The authors suggest that these increases may be the result of an accelerated nutrition transition to a high-fat, Western diet. However, it is important to note that these intake data were collected over 10 years ago and therefore, dietary fat intakes may have since changed further.

SFA intakes in Irish children (14\% TE) are similar to intakes in children across Europe and America ${ }^{(6,45)}$. The highest SFA intakes in Europe were found in Danish girls aged $4-5$ years at 16 $\% \mathrm{TE}$, whereas Italian males aged $7-9$ years had the lowest at $9.4 \% \mathrm{TE}^{(6)}$. A comprehensive review which investigated compliance to dietary fat recommendations by children across the WHO European region found that children in all eighteen countries examined exceeded the WHO SFA recommendation of less than $10 \% \mathrm{TE}^{(46)}$. SFA compliance in neighbouring UK children was reported by Pot et al. who demonstrated that the proportion of children aged $4-10$ years meeting the UK SFA guideline of less than $11 \%$ TE was $14 \%{ }^{(42)}$. To note, although this is higher than the compliance rate reported in Irish children (7\%), it remains extremely poor. Moreover, if the authors examined SFA compliance based on current SFA cut-offs (less than $10 \% \mathrm{TE}$ ), compliance would undoubtedly be lower in UK children. The evidence linking elevated SFA intakes to CVD risk is 
Accepted manuscript

irrefutable and the extreme low levels of SFA compliance observed in children across the globe highlights the severity of the issue. Therefore, it is imperative that strategies are devised to reduce SFA intakes in children in order to reduce the risk of CVD and other chronic diseases in later life.

The main food sources of SFA in Irish children continue to be 'whole milk', 'biscuits, cakes, pastries and buns', 'meat products' and 'cheeses', which are similar to the food sources of SFA in Irish adolescents, as well as 'sugars, confectionary and preserves' ${ }^{(9)}$. In addition to 'cheeses' and 'meat products', the top sources contributing to Irish adult SFA intakes include 'fresh meat' and 'spreading fats and oils ${ }^{(41)}$. Dairy and meat products are among the overall top contributors of SFA across many European countries and the US, which is in agreement with the current findings ${ }^{(47-49)}$. Despite a $9 \%$ reduction in SFA from whole milk since 2005, it remains the top contributor to SFA intakes in Irish children. Nevertheless, this decrease observed in the contribution of whole milk and the increase observed in low-fat milk across all fatty acids may reflect a change in dietary habits. Potentially, adherence to dietary guidelines advocating the consumption of low-fat over whole milk has improved. Although, given the body of evidence in support of the dairy food matrix, whereby interactions between its food components are thought to potentially alter the properties of the nutrients, SFA from dairy products may not be a cause for concern as emerging evidence suggests it could be beneficial in terms of cardiovascular health ${ }^{(50)}$. On balance, intakes of overall milk have reduced and whole milk intakes have not been compensated for despite increases in low-fat milk ${ }^{(15)}$, which could have implications for intakes of other nutrients such as calcium and iodine.

The current intakes of trans fat have decreased by $0.02 \%$ TE since 2005 and remain within the recommendation of less than $2 \% \mathrm{TE}^{(7,38)}$. Few countries provided data for trans fat intakes in children; of the countries that have $(n=4)$, intakes ranged between $0.6-1.8 \%$ of $\mathrm{TE}^{(6)}$ which is higher than the $0.5 \%$ reported in the present study but still within the general recommendation. As expected, the main contributions to trans fat in the diet of Irish children are derived from animalbased products such as dairy and meat. However, an increase in the contribution of 'biscuits, cakes, pastries and buns' has resulted in this food group becoming the $4^{\text {th }}$ contributor. While there is the possibility that the trans fat composition of these food products has increased, the considerable efforts over the years to reduce industrial sources of trans fat in Ireland deem this unlikely ${ }^{(12)}$. As the increase is reflected across all fatty acids, it is more likely due to increases in the consumption of these products.

The intakes of PUFA in Irish children $(5.6 \% \mathrm{TE})$ is similar to European intakes $(4-9 \% \mathrm{TE})^{(6)}$ and, although the adherence level to PUFA intake recommendations has increased from 60 to $71 \%$, further improvement is warranted. Some of the main food sources of PUFA in Irish children include 
'biscuits, cakes, pastries and buns' and 'meat products', which are also significant contributors of SFA intakes. Therefore, promoting a reduction in these foods to improve SFA intakes, could have unfavourable consequences for PUFA intakes. This demonstrates the complexities of devising strategies to improve the dietary fat profile within a population. In addition, EPA and DHA intakes (105 mg/day combined), which includes intake from nutritional supplements, is considerably lower than the adequate intake of $250 \mathrm{mg}$ /day proposed by $\mathrm{EFSA}^{(6)}$. Similar low adherence was found in children from other European countries such as France (6 - 10 years; $154 \mathrm{mg} /$ day), Belgium (4 - 6 years; $75 \mathrm{mg} /$ day) and Germany $(4-12 \text { years; } 62-85 \mathrm{mg} / \text { day })^{(51-53)}$. Given the health benefits of EPA and DHA such as supporting brain function and cognitive development in children ${ }^{(54)}$, as well as their potential role in CVD prevention ${ }^{(55)}$, this pattern of low adherence to EPA and DHA guidelines may signify a greater global issue of insufficient $n$-3 intakes in children. The two major contributors to EPA and DHA intakes in the current study were 'fish, fish products and fish dishes' and 'fresh meat', which are in line with the main contributors reported in Irish adults ${ }^{(41)}$, as well as those reported in the $\mathrm{UK}^{(42)}$ and other countries ${ }^{(51,53,56,57)}$. However, the consumption of these foods, in particular fish, is typically below the recommended dietary guidelines ${ }^{(52,58)}$. This can be due to cultural food practices and preferences, denoting that other dietary sources may be required to increase EPA and DHA intakes.

Although intakes of particular subtypes of dietary fat are deemed inadequate, namely SFA and overall PUFA, total fat intakes remain in line with total fat recommendations. The mean total fat intake in Irish children is $33 \%$ TE, with no significant changes in intake noted since 2005 . These intakes are similar to the total fat intakes reported in children and adolescents across Europe, which range between $28-42 \% \mathrm{TE}^{(6)}$. Rippin et al. found that total fat compliance to recommendations for intake of total fat was particularly poor in Europe, as children in only two of the eighteen European countries examined had intake levels below the WHO recommended maximum value of $\leq 30 \% \mathrm{TE}^{(46)}$. Furthermore, in the UK, only $47 \%$ of children complied with UK recommendations of total fat intake $(\leq 33 \% \mathrm{TE})^{(42)}$. However, as the most recent cut-off stands at $\leq 35 \% \mathrm{TE}$, increases in the percentage of UK children complying with the current recommendation is likely ${ }^{(6,}$ ${ }^{38)}$. It is worth noting that if the UK or WHO guidelines were used as the cut-off in the current study, the mean intake of total fat in Irish children would exceed both recommendations. 
The current analysis has many strengths such as the high quality of dietary data derived from weighed food records collected for both national food consumption surveys. Furthermore, data were obtained from current food composition tables and databases, brand information and published papers to ensure the most up-to-date fatty acid concentrations were assigned to all foods contained in the food consumption database and to achieve the most accurate estimates of fatty acid intake. Further considerations to assess usual intakes in this paper also provided more accuracy for estimating nutrient intakes. This method of estimation observes the long-term nutrient and dietary intake rather than the reported intake over a few days. Therefore, this method permits direct comparative analysis across the two surveys, irrespective of the different number of recording days (7-day and 4-day) without compromising the study results. However, due to the self-reporting nature of these dietary assessments, this study may be limited due to under-reporting. Albeit the levels of under-reporting have decreased from $33 \%$ in 2005 to $20 \%$ in 2019 (data not shown), under-reporters were not excluded from the analysis. Although the methodologies in both surveys are similar due to their cross-sectional design, the comparative data is limited for evaluating the effectiveness of public health initiatives compared with longitudinal trend analysis.

In conclusion, improvements have been made to the dietary fat profile of Irish children over the last number of years, with slight reductions observed in SFA and trans fat intakes and increases detected across all reported unsaturated fats. Nevertheless, while progress has been made, adherence to SFA, PUFA, EPA and DHA recommendations remains inadequate and, therefore, improvements need to be made to the quality of dietary fat consumed. In the past, food reformulation has played a significant role in the success of limiting the consumption of trans fat. Therefore, further considerations to reformulate foods could have a positive impact on fatty acid intakes, particularly in the context of SFA and PUFA. Considerations should also be made to promote foods containing a more favourable dietary fat profile. However, caution is warranted when considering strategies to promote individual nutrient recommendations and perhaps a holistic dietary approach would be more effective. 
Accepted manuscript

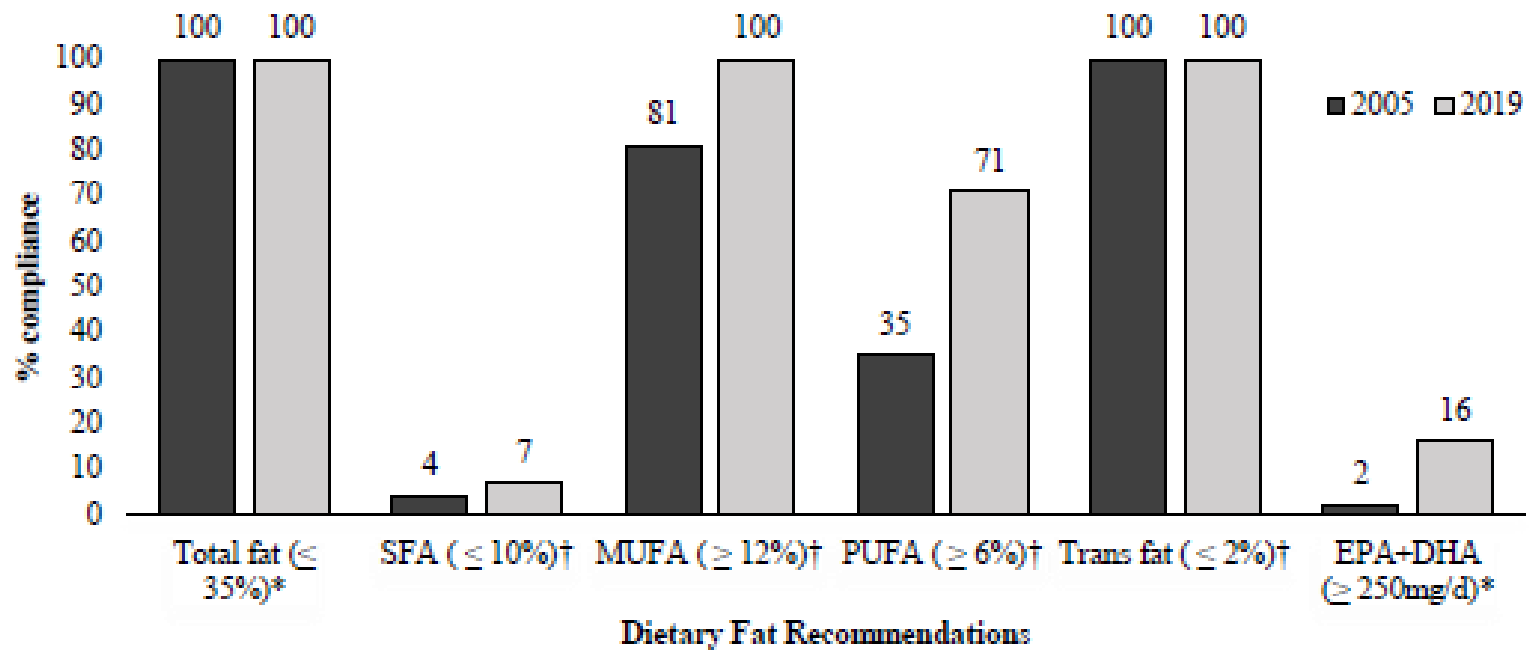

Figure 1: Percentage of Irish children adhering to current EFSA and UK dietary recommendations for total fat and fatty acids between 2005 and 2019.

SFA, saturated fatty acid; MUFA, monounsaturated fatty acid; PUFA, polyunsaturated fatty acid; EPA, eicosapentaenoic acid; DHA, docosahexaenoic acid; *Targets from EFSA ${ }^{(6)}$; $†$ Targets from the Department of Health and/or Scientific Advisory Committee on Nutrition $^{(7,38)}$. 


\section{Accepted manuscript}

Table 1. Intakes of total fat intake ( $\mathrm{g}$ or $\mathrm{mg} /$ day and $\% \mathrm{TE}$ ) and its constituent fatty acids in Irish children in 2019

\begin{tabular}{|c|c|c|c|c|c|c|c|c|c|c|c|c|}
\hline & & & \multicolumn{5}{|c|}{ Gender } & \multicolumn{5}{|c|}{ Age } \\
\hline & \multicolumn{2}{|c|}{ Total population } & \multicolumn{2}{|c|}{ Boy } & \multicolumn{3}{|c|}{ Girl } & \multicolumn{2}{|c|}{$5-8$ years } & \multicolumn{2}{|c|}{$9-12$ years } & \multirow[b]{3}{*}{$P^{*}$} \\
\hline & \multicolumn{2}{|c|}{$(n 600)$} & \multicolumn{2}{|c|}{$(n 300)$} & \multicolumn{2}{|c|}{$(n 300)$} & & \multicolumn{2}{|c|}{$(n 300)$} & \multicolumn{2}{|c|}{$(n 300)$} & \\
\hline & Mean & SD & Mean & SD & Mean & SD & $P^{*}$ & Mean & SD & Mean & SD & \\
\hline Energy (kcal) & 1487 & 275 & 1583 & 280 & 1398 & 238 & $<0.001$ & 1380 & 234 & 1600 & 270 & $<0.001$ \\
\hline Total fat (g/d) & 55.8 & 12.7 & 59.2 & 13.2 & 52.7 & 11.3 & $<0.001$ & 51.6 & 11.0 & 60.3 & 12.8 & $<0.001$ \\
\hline $\operatorname{SFA}(g / d)$ & 23.4 & 5.59 & 24.7 & 5.75 & 22.2 & 5.18 & $<0.001$ & 22.1 & 5.20 & 24.8 & 5.67 & $<0.001$ \\
\hline MUFA (g/d) & 22.9 & 5.55 & 24.4 & 5.83 & 21.5 & 4.89 & $<0.001$ & 20.8 & 4.67 & 25.1 & 5.57 & $<0.001$ \\
\hline PUFA (g/d) & 9.28 & 2.47 & 9.95 & 2.63 & 8.67 & 2.13 & $<0.001$ & 8.51 & 2.09 & 10.1 & 2.57 & $<0.001$ \\
\hline Omega 6 (g/d) & 6.00 & 1.59 & 6.49 & 1.69 & 5.55 & 1.35 & $<0.001$ & 5.45 & 1.32 & 6.59 & 1.65 & $<0.001$ \\
\hline Omega $3(\mathrm{~g} / \mathrm{d})$ & 1.23 & 0.39 & 1.29 & 0.41 & 1.18 & 0.36 & $<0.001$ & 1.15 & 0.35 & 1.33 & 0.41 & $<0.001$ \\
\hline Trans fat (g/d) & 0.84 & 0.28 & 0.88 & 0.29 & 0.80 & 0.27 & $<0.001$ & 0.80 & 0.27 & 0.88 & 0.29 & $<0.001$ \\
\hline $\operatorname{ALA}(\mathrm{g} / \mathrm{d})$ & 0.99 & 0.31 & 1.05 & 0.33 & 0.94 & 0.29 & $<0.001$ & 0.91 & 0.27 & 1.08 & 0.33 & $<0.001$ \\
\hline EPA (mg/d) & 41.7 & 32.5 & 45.6 & 35.7 & 38.1 & 28.8 & $<0.001$ & 39.2 & 29.2 & 44.3 & 35.5 & $<0.001$ \\
\hline DHA (mg/d) & 63.7 & 50.5 & 68.6 & 54.8 & 59.2 & 45.9 & $<0.001$ & 61.1 & 46.6 & 66.5 & 54.3 & $<0.001$ \\
\hline Total fat (\%TE) & 33.3 & 3.83 & 33.2 & 3.85 & 33.4 & 3.80 & $<0.001$ & 33.1 & 3.85 & 33.5 & 3.78 & $<0.001$ \\
\hline SFA (\%TE) & 14.0 & 2.15 & 13.9 & 2.15 & 14.2 & 2.14 & $<0.001$ & 14.2 & 2.17 & 13.8 & 2.12 & $<0.001$ \\
\hline MUFA (\%TE) & 13.6 & 1.79 & 13.6 & 1.82 & 13.6 & 1.77 & $<0.001$ & 13.3 & 1.77 & 13.9 & 1.77 & $<0.001$ \\
\hline PUFA (\%TE) & 5.55 & 0.98 & 5.58 & 1.00 & 5.52 & 0.97 & $<0.001$ & 5.49 & 0.97 & 5.62 & 0.99 & $<0.001$ \\
\hline Omega 6 (\%TE) & 3.58 & 0.61 & 3.64 & 0.62 & 3.52 & 0.59 & $<0.001$ & 3.50 & 0.59 & 3.66 & 0.62 & $<0.001$ \\
\hline Omega 3 (\%TE) & 0.74 & 0.18 & 0.72 & 0.18 & 0.75 & 0.18 & $<0.001$ & 0.74 & 0.18 & 0.74 & 0.18 & $<0.001$ \\
\hline Trans fat (\%TE) & 0.51 & 0.14 & 0.50 & 0.14 & 0.51 & 0.15 & $<0.001$ & 0.51 & 0.15 & 0.50 & 0.14 & $<0.001$ \\
\hline ALA (\%TE) & 0.61 & 0.16 & 0.60 & 0.16 & 0.61 & 0.16 & $<0.001$ & 0.60 & 0.16 & 0.62 & 0.16 & $<0.001$ \\
\hline EPA (\%TE) & 0.03 & 0.02 & 0.03 & 0.02 & 0.02 & 0.02 & $<0.001$ & 0.03 & 0.02 & 0.03 & 0.02 & $<0.001$ \\
\hline DHA (\%TE) & 0.04 & 0.03 & 0.04 & 0.03 & 0.04 & 0.03 & $<0.001$ & 0.04 & 0.03 & 0.04 & 0.03 & $<0.001$ \\
\hline
\end{tabular}




\section{Accepted manuscript}

Table 2. Comparison of total fat intake (g or mg/day and \% TE) and its constituent fatty acids in Irish children in 2005 and 2019 by gender

\begin{tabular}{|c|c|c|c|c|c|c|c|c|c|c|c|c|c|c|c|}
\hline & \multicolumn{5}{|c|}{ Total Population } & \multicolumn{10}{|c|}{ Gender } \\
\hline & \multicolumn{2}{|c|}{2005} & \multicolumn{2}{|c|}{2019} & \multirow[b]{4}{*}{$P^{*}$} & \multicolumn{2}{|c|}{2005} & \multicolumn{2}{|c|}{2019} & & \multicolumn{2}{|c|}{2005} & \multicolumn{2}{|c|}{2019} & \multirow[b]{4}{*}{$P^{*}$} \\
\hline & \multirow{2}{*}{\multicolumn{2}{|c|}{$(n 594)$}} & \multirow{2}{*}{\multicolumn{2}{|c|}{$(n 600)$}} & & \multirow{2}{*}{\multicolumn{2}{|c|}{$\frac{\text { Boy }}{(n 293)}$}} & \multicolumn{2}{|c|}{ Boy } & & \multicolumn{2}{|c|}{ Girl } & \multicolumn{2}{|c|}{ Girl } & \\
\hline & & & & & & & & & & & & & & & \\
\hline & Mean & $\mathrm{SD}$ & Mean & SD & & Mean & SD & Mean & SD & $P^{*}$ & Mean & SD & Mean & $\mathrm{SD}$ & \\
\hline Energy (kcal) & 1667 & 323 & 1487 & 275 & $<0.001$ & 1756 & 327 & 1583 & 280 & $<0.001$ & 1581 & 295 & 1398 & 238 & $<0.001$ \\
\hline Total fat $(\mathrm{g} / \mathrm{d})$ & 63.1 & 14.2 & 55.8 & 12.7 & $<0.001$ & 65.5 & 14.6 & 59.2 & 13.2 & $<0.001$ & 60.7 & 13.5 & 52.7 & 11.3 & $<0.001$ \\
\hline $\mathrm{SFA}(\mathrm{g} / \mathrm{d})$ & 27.3 & 6.69 & 23.4 & 5.59 & $<0.001$ & 28.4 & 6.84 & 24.7 & 5.75 & $<0.001$ & 26.1 & 6.34 & 22.2 & 5.18 & $<0.001$ \\
\hline MUFA (g/d) & 21.5 & 5.06 & 22.9 & 5.55 & $<0.001$ & 22.4 & 5.18 & 24.4 & 5.83 & $<0.001$ & 20.7 & 4.81 & 21.5 & 4.89 & 0.594 \\
\hline PUFA (g/d) & 9.17 & 2.77 & 9.28 & 2.47 & 1.000 & 9.42 & 2.83 & 9.95 & 2.63 & 0.180 & 8.92 & 2.68 & 8.67 & 2.13 & 1.000 \\
\hline Omega $6(\mathrm{~g} / \mathrm{d})$ & 5.77 & 1.64 & 6.00 & 1.59 & 0.018 & 5.95 & 1.68 & 6.49 & 1.69 & $<0.001$ & 5.61 & 1.58 & 5.55 & 1.35 & 1.000 \\
\hline Omega $3(\mathrm{~g} / \mathrm{d})$ & 1.03 & 0.36 & 1.23 & 0.39 & $<0.001$ & 1.05 & 0.36 & 1.29 & 0.41 & $<0.001$ & 1.02 & 0.35 & 1.18 & 0.36 & $<0.001$ \\
\hline Trans-fat $(\mathrm{g} / \mathrm{d})$ & 1.00 & 0.29 & 0.84 & 0.28 & $<0.001$ & 1.03 & 0.30 & 0.88 & 0.29 & $<0.001$ & 0.96 & 0.28 & 0.80 & 0.27 & $<0.001$ \\
\hline $\operatorname{ALA}(\mathrm{g} / \mathrm{d})$ & - & - & 0.99 & 0.31 & - & - & - & 1.05 & 0.33 & - & - & - & 0.94 & 0.29 & - \\
\hline $\operatorname{EPA}(\mathrm{mg} / \mathrm{d})$ & 27.0 & 18.6 & 41.7 & 32.5 & $<0.001$ & 28.5 & 19.6 & 45.6 & 35.7 & $<0.001$ & 25.5 & 17.6 & 38.1 & 28.8 & $<0.001$ \\
\hline DHA (mg/d) & 36.4 & 25.1 & 63.7 & 50.5 & $<0.001$ & 38.4 & 26.3 & 68.6 & 54.8 & $<0.001$ & 34.6 & 23.7 & 59.2 & 45.9 & $<0.001$ \\
\hline Total fat (\%TE) & 33.7 & 3.58 & 33.3 & 3.83 & 0.918 & 33.3 & 3.57 & 33.2 & 3.85 & 1.000 & 34.1 & 3.53 & 33.4 & 3.80 & 0.018 \\
\hline SFA (\%TE) & 14.5 & 2.14 & 14.0 & 2.15 & $<0.001$ & 14.4 & 2.14 & 13.9 & 2.15 & $<0.001$ & 14.7 & 2.13 & 14.2 & 2.14 & $<0.001$ \\
\hline MUFA (\%TE) & 11.5 & 1.49 & 13.6 & 1.79 & $<0.001$ & 11.4 & 1.48 & 13.6 & 1.82 & $<0.001$ & 11.6 & 1.49 & 13.6 & 1.77 & $<0.001$ \\
\hline PUFA (\%TE) & 4.89 & 1.03 & 5.55 & 0.98 & $<0.001$ & 4.78 & 1.00 & 5.58 & 1.00 & $<0.001$ & 5.01 & 1.05 & 5.52 & 0.97 & $<0.001$ \\
\hline Omega 6 (\%TE) & 3.10 & 0.59 & 3.58 & 0.61 & $<0.001$ & 3.03 & 0.58 & 3.64 & 0.62 & $<0.001$ & 3.16 & 0.60 & 3.52 & 0.59 & $<0.001$ \\
\hline Omega 3 (\%TE) & 0.56 & 0.15 & 0.74 & 0.18 & $<0.001$ & 0.53 & 0.14 & 0.72 & 0.18 & $<0.001$ & 0.58 & 0.15 & 0.75 & 0.18 & $<0.001$ \\
\hline Trans-fat (\%TE) & 0.53 & 0.12 & 0.51 & 0.14 & $<0.001$ & 0.53 & 0.12 & 0.50 & 0.14 & $<0.001$ & 0.54 & 0.12 & 0.51 & 0.15 & $<0.001$ \\
\hline ALA (\%TE) & - & - & 0.61 & 0.16 & - & - & - & 0.60 & 0.16 & - & - & - & 0.61 & 0.16 & - \\
\hline EPA (\%TE) & 0.01 & 0.01 & 0.03 & 0.02 & $<0.001$ & 0.02 & 0.01 & 0.03 & 0.02 & $<0.001$ & 0.015 & 0.009 & 0.02 & 0.02 & $<0.001$ \\
\hline DHA (\%TE) & 0.02 & 0.01 & 0.04 & 0.03 & $<0.001$ & 0.02 & 0.01 & 0.04 & 0.03 & $<0.001$ & 0.020 & 0.012 & 0.04 & 0.03 & $<0.001$ \\
\hline
\end{tabular}

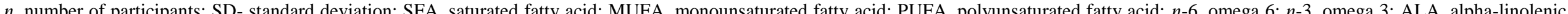

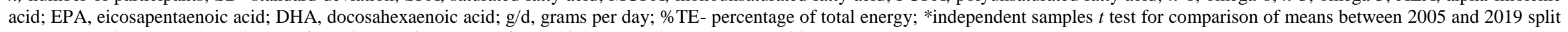
by gender, adjusted $P$ value using Bonferroni correction method for multiple comparisons was also utilised. 


\section{Accepted manuscript}

Table 3a. Percentage contribution of food groups to total fat, SFA, MUFA and PUFA intakes in Irish children in 2005 and 2019

\begin{tabular}{|c|c|c|c|c|c|c|c|c|c|c|c|c|}
\hline & \multicolumn{3}{|c|}{ Total fat } & \multicolumn{3}{|c|}{ SFA } & \multicolumn{3}{|c|}{ MUFA } & \multicolumn{3}{|c|}{ PUFA } \\
\hline & 2005 & 2019 & & 2005 & 2019 & & 2005 & 2019 & & 2005 & 2019 & \\
\hline & $(n 594)$ & $(n 600)$ & $P^{*}$ & $(n 594)$ & $(n 600)$ & $P^{*}$ & $(n 594)$ & $(n 600)$ & $P^{*}$ & $(n 594)$ & $(n 600)$ & $P^{*}$ \\
\hline Fresh meat & 4.9 & 5.8 & 0.003 & 4.1 & 4.7 & 0.042 & 6.1 & 7.0 & 0.019 & 4.6 & 5.9 & $<0.001$ \\
\hline Meat dishes & 4.2 & 6.3 & $<0.001$ & 3.6 & 5.9 & $<0.001$ & 4.9 & 7.4 & $<0.001$ & 3.9 & 4.9 & 0.012 \\
\hline Meat products & 9.9 & 9.2 & 0.142 & 8.3 & 7.5 & 0.064 & 12.1 & 10.6 & 0.008 & 10.4 & 9.8 & 0.233 \\
\hline Whole milk & 14.8 & 8.3 & $<0.001$ & 21.1 & 12.2 & $<0.001$ & 11.4 & 6.9 & $<0.001$ & 2.9 & 1.7 & $<0.001$ \\
\hline Low fat, skimmed \& fortified milks & 0.7 & 1.4 & $<0.001$ & 1.1 & 2.1 & $<0.001$ & 0.6 & 1.3 & $<0.001$ & 0.2 & 0.1 & 0.139 \\
\hline Cheeses & 3.3 & 5.3 & $<0.001$ & 4.7 & 7.7 & $<0.001$ & 2.7 & 4.4 & $<0.001$ & 0.8 & 1.4 & $<0.001$ \\
\hline Butter & 2.1 & 3.5 & $<0.001$ & 2.8 & 5.0 & $<0.001$ & 1.7 & 2.8 & $<0.001$ & 0.6 & 1.0 & $<0.001$ \\
\hline Low-fat spreads & 1.0 & 0.3 & $<0.001$ & 0.6 & 0.2 & $<0.001$ & 1.0 & 0.3 & $<0.001$ & 2.7 & 0.7 & $<0.001$ \\
\hline Spreading fats and oils & 6.1 & 4.3 & $<0.001$ & 4.4 & 3.5 & 0.002 & 7.7 & 4.8 & $<0.001$ & 9.6 & 5.1 & $<0.001$ \\
\hline Ice cream and creams & 2.8 & 1.9 & $<0.001$ & 4.2 & 3.0 & $<0.001$ & 2.0 & 1.3 & $<0.001$ & 0.7 & 0.5 & $<0.001$ \\
\hline Puddings and chilled desserts & 3.5 & 4.0 & 0.086 & 4.2 & 4.6 & 0.131 & 3.2 & 3.4 & 0.399 & 1.9 & 3.7 & $<0.001$ \\
\hline Savouries & 3.9 & 5.1 & 0.002 & 3.3 & 5.0 & $<0.001$ & 4.1 & 5.0 & 0.018 & 5.2 & 5.8 & 0.139 \\
\hline Savoury snacks & 6.0 & 3.8 & $<0.001$ & 4.7 & 2.2 & $<0.001$ & 6.9 & 5.4 & $<0.001$ & 8.8 & 3.8 & $<0.001$ \\
\hline Soups, sauces \& miscellaneous foods & 1.7 & 2.3 & 0.004 & 1.0 & 1.6 & $<0.001$ & 1.3 & 2.6 & $<0.001$ & 3.0 & 3.2 & 0.734 \\
\hline Biscuits, cakes pastries \& buns & 7.6 & 10.4 & $<0.001$ & 8.7 & 11.8 & $<0.001$ & 7.8 & 9.8 & $<0.001$ & 5.6 & 9.0 & $<0.001$ \\
\hline Sugars, confectionary \& preserves & 8.3 & 6.1 & $<0.001$ & 10.3 & 7.3 & $<0.001$ & 8.7 & 6.0 & $<0.001$ & 3.5 & 3.5 & 0.976 \\
\hline Potatoes & 0.7 & 0.8 & 0.754 & 0.8 & 1.1 & 0.065 & 0.4 & 0.6 & 0.024 & 1.4 & 0.5 & $<0.001$ \\
\hline Potatoes chipped, fired \& roasted potatoes & 5.8 & 3.3 & $<0.001$ & 3.9 & 1.6 & $<0.001$ & 6.9 & 3.9 & $<0.001$ & 9.9 & 5.7 & $<0.001$ \\
\hline Potato products & 0.7 & 0.8 & 0.514 & 0.3 & 0.3 & 0.724 & 0.6 & 0.8 & 0.022 & 2.5 & 2.0 & 0.104 \\
\hline Fish, fish products $\&$ fish dishes & 1.2 & 2.1 & $<0.001$ & 0.7 & 1.0 & 0.051 & 1.3 & 2.5 & $<0.001$ & 2.6 & 3.7 & 0.002 \\
\hline Eggs \& egg dishes & 1.8 & 2.3 & 0.030 & 1.6 & 1.9 & 0.165 & 2.0 & 2.6 & 0.019 & 1.4 & 2.6 & $<0.001$ \\
\hline Vegetable \& pulse dishes & 0.7 & 0.6 & 0.502 & 0.3 & 0.4 & 0.471 & 0.6 & 0.7 & 0.682 & 2.0 & 1.0 & 0.001 \\
\hline Breads \& rolls & 3.7 & 5.2 & $<0.001$ & 2.3 & 3.7 & $<0.001$ & 2.9 & 4.7 & $<0.001$ & 6.9 & 10.9 & $<0.001$ \\
\hline RTEBC & 1.3 & 1.7 & $<0.001$ & 0.9 & 1.2 & 0.007 & 0.9 & 1.5 & $<0.001$ & 2.9 & 3.9 & $<0.001$ \\
\hline Other $\uparrow$ & 3.0 & 5.0 & $<0.001$ & 2.1 & 4.5 & $<0.001$ & 2.3 & 3.7 & $<0.001$ & 5.6 & 9.2 & $<0.001$ \\
\hline
\end{tabular}

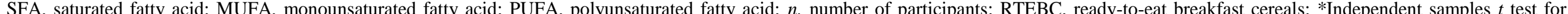

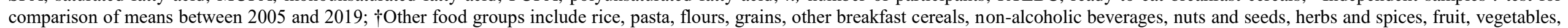
other milk and milk-based beverages. 


\section{Accepted manuscript}

Table 3b. Percentage contribution of food groups to ALA, EPA, DHA and Trans fat intakes in Irish children in 2005 and 2019

\begin{tabular}{|c|c|c|c|c|c|c|c|c|c|c|c|c|}
\hline & \multicolumn{3}{|c|}{ ALA } & \multicolumn{3}{|c|}{$\mathrm{EPA}$} & \multicolumn{3}{|c|}{ DHA } & \multicolumn{3}{|c|}{ Trans fat } \\
\hline & 2005 & 2019 & & 2005 & 2019 & & 2005 & 2019 & & 2005 & 2019 & \\
\hline & $(n 594)$ & $(n 600)$ & $P^{*}$ & $(n 594)$ & $(n 600)$ & $P^{*}$ & $(n 594)$ & $(n 600)$ & $P^{*}$ & $(n 594)$ & $(n 600)$ & $P^{*}$ \\
\hline Fresh meat & - & 5.3 & - & 18.0 & 17.3 & 0.505 & 23.2 & 21.3 & 0.153 & 5.4 & 5.7 & 0.532 \\
\hline Meat dishes & - & 6.2 & - & 8.0 & 4.8 & $<0.001$ & 5.7 & 4.5 & 0.062 & 6.6 & 12.1 & $<0.001$ \\
\hline Meat products & - & 10.9 & - & 7.5 & 4.9 & $<0.001$ & 14.6 & 6.9 & $<0.001$ & 11.6 & 7.2 & $<0.001$ \\
\hline Whole milk & - & 1.6 & - & 22.9 & 15.5 & $<0.001$ & 13.3 & 8.1 & $<0.001$ & 17.1 & 12.2 & $<0.001$ \\
\hline Low fat, skimmed \& fortified milks & - & 0.1 & - & 0.9 & 3.3 & $<0.001$ & 0.3 & 1.0 & $<0.001$ & 1.9 & 4.8 & $<0.001$ \\
\hline Cheeses & - & 2.4 & - & 5.0 & 8.3 & $<0.001$ & 2.9 & 4.1 & $<0.001$ & 9.4 & 14.4 & $<0.001$ \\
\hline Butter & - & 1.3 & - & 3.2 & 5.3 & $<0.001$ & 1.6 & 2.7 & 0.001 & 5.3 & 7.6 & 0.001 \\
\hline Low-fat spreads & - & 0.9 & - & 0.5 & 0.0 & $<0.001$ & 0.0 & 0.0 & 1.000 & 0.2 & 0.1 & 0.002 \\
\hline Spreading fats and oils & - & 10.1 & - & 5.5 & 0.4 & $<0.001$ & 0.0 & 0.0 & 1.000 & 2.5 & 1.0 & $<0.001$ \\
\hline Ice cream and creams & - & 0.4 & - & 0.3 & 1.2 & $<0.001$ & 0.1 & 0.1 & 0.871 & 3.1 & 1.9 & $<0.001$ \\
\hline Puddings and chilled desserts & - & 3.2 & - & 2.6 & 3.0 & 0.279 & 2.1 & 4.5 & $<0.001$ & 3.2 & 2.9 & 0.382 \\
\hline Savouries & - & 6.8 & - & 0.8 & 0.8 & 0.913 & 1.7 & 2.4 & 0.122 & 3.2 & 3.5 & $<0.001$ \\
\hline Savoury snacks & - & 3.5 & - & 0.0 & 0.0 & 1.000 & 0.1 & 0.0 & 0.012 & 1.9 & 0.4 & $<0.001$ \\
\hline Soups, sauces \& miscellaneous foods & - & 4.8 & - & 0.3 & 0.8 & 0.030 & 0.2 & 0.1 & 0.011 & 4.7 & 1.9 & $<0.001$ \\
\hline Biscuits, cakes pastries \& buns & - & 8.5 & - & 0.6 & 3.9 & $<0.001$ & 1.3 & 3.6 & $<0.001$ & 5.2 & 8.9 & $<0.001$ \\
\hline Sugars, confectionary \& preserves & - & 1.4 & - & 0.0 & 0.0 & 0.283 & 0.0 & 0.0 & 0.721 & 5.4 & 2.1 & $<0.001$ \\
\hline Potatoes & - & 1.7 & - & 0.2 & 0.2 & 0.814 & 0.0 & 0.0 & 0.814 & 1.2 & 1.7 & 0.054 \\
\hline Potatoes chipped, fired \& roasted potatoes & - & 2.0 & - & 0.0 & 0.0 & 0.374 & 0.0 & 0.0 & 1.000 & 3.9 & 1.2 & $<0.001$ \\
\hline Potato products & - & 1.4 & - & 0.0 & 0.0 & 0.464 & 0.0 & 0.1 & 0.060 & 0.8 & 0.3 & $<0.001$ \\
\hline Fish, fish products $\&$ fish dishes & - & 3.5 & - & 19.4 & 24.0 & 0.012 & 21.8 & 26.6 & 0.013 & 1.4 & 0.3 & $<0.001$ \\
\hline Eggs \& egg dishes & - & 1.5 & - & 0.5 & 1.3 & 0.006 & 8.3 & 11.4 & 0.003 & 1.9 & 1.4 & 0.035 \\
\hline Vegetable \& pulse dishes & - & 1.3 & - & 0.3 & 0.2 & 0.583 & 0.5 & 0.0 & 0.021 & 0.5 & 0.4 & 0.558 \\
\hline Breads \& rolls & - & 9.8 & - & 0.9 & 2.3 & $<0.001$ & 0.1 & 0.3 & 0.086 & 2.4 & 2.6 & 0.332 \\
\hline RTEBC & - & 2.5 & - & 0.0 & 0.0 & 1.000 & 0.0 & 0.0 & 1.000 & 0.2 & 0.1 & 0.279 \\
\hline Other† & - & 8.2 & - & 0.7 & 0.0 & $<0.001$ & 0.5 & 0.1 & 0.057 & 1.1 & 5.2 & $<0.001$ \\
\hline Nutritional supplements & - & 0.5 & - & 1.9 & 2.0 & 0.886 & 1.8 & 1.8 & 0.980 & 0.0 & 0.0 & 1.000 \\
\hline
\end{tabular}

Nutritional supplements

0.886

0.980

1.000

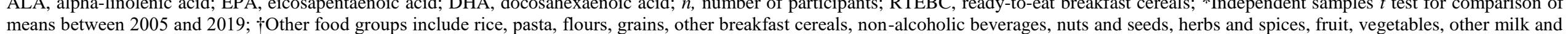
milk-based beverages. 


\section{References}

1. Calder PC (2011). Fatty acids and inflammation: the cutting edge between food and pharma. Eur J Pharmacol 668, S50-S8.

2. Berg JM, Tymoczko JL, Stryer L (2012). Biochemistry. Chapter 22: Fatty Acid Metabolism. 7th ed. New York: WH Freeman and Company.

3. Schwab U, Lauritzen L, Tholstrup T, et al. (2014). Effect of the amount and type of dietary fat on cardiometabolic risk factors and risk of developing type 2 diabetes, cardiovascular diseases, and cancer: a systematic review. Food Nutr Res 58, doi:10.3402/fnr.v58.25145.

4. Birch L, Savage JS, Ventura A (2007). Influences on the development of children's eating behaviours: from infancy to adolescence. Can J Diet Pract Res 68(1), S1-S56.

5. Food and Agriculture Organization of the United Nations (2010). Fats and fatty acids in human nutrition. Report of an expert consultation. Rome: FAO.

6. European Food Safety Authority (2010). Scientific opinion on dietary reference values for fats, including saturated fatty acids, polyunsaturated fatty acids, monounsaturated fatty acids, trans fatty acids, and cholesterol. EFSA $J$ 8(3), 1461.

7. Scientific Advisory Commitee on Nutrition (2019). Saturated fats and health. Public Health England and UK Health Departments.

https://assets.publishing.service.gov.uk/government/uploads/system/uploads/attachment_data/file/8 14995/SACN_report_on_saturated_fat_and_health.pdf (accessed May 2020).

8. Harika RK, Cosgrove MC, Osendarp SJM, et al. (2011). Fatty acid intakes of children and adolescents are not in line with the dietary intake recommendations for future cardiovascular health: a systematic review of dietary intake data from thirty countries. Br J Nutr 106(3), 307-16.

9. Joyce T, Wallace AJ, McCarthy SN, et al. (2009). Intakes of total fat, saturated, monounsaturated and polyunsaturated fatty acids in Irish children, teenagers and adults. Public Health Nutr 12(2), 156-65.

10. Safefood (2017). START. https://www.safefood.eu/Utility/AboutUs/Campaigns/START.aspx (accessed May 2020).

11. Food Standards Agency (2018). Saturated Fat. https://www.food.gov.uk/safetyhygiene/saturated-fat (accessed May 2020).

12. Food Safety Authority of Ireland (2016). Survey of the trans fatty acid content in processed food products in Ireland. Dublin: FSAI.

13. van der Velde LA, Nguyen AN, Schoufour JD, et al. (2019). Diet quality in childhood: the Generation R Study. Eur J Nutr 58(3), 1259-69. 
14. Irish Universities Nutrition Alliance (2005). National Children's Food Survey. https://www.iuna.net/surveyreports (accessed May 2020).

15. Irish Universities Nutrition Alliance (2019). National Children's Foody Survey II Summary Report. https://www.iuna.net/surveyreports (accessed May 2020).

16. Central Statistics Office (2003). Census 2002 Principal Demographic Results, Dublin: The Stationary Office.

17. Central Statistics Office (2017). Census 2016 Summary Results - Part 1. Ireland: Central Statistics Office.

https://www.cso.ie/en/media/csoie/newsevents/documents/census2016summaryresultspart1/Census 2016SummaryPart1.pdf (accessed May 2020).

18. Department of Education and Skills (2016). Data on Individual Schools. https://www.education.ie/en/Publications/Statistics/Data-on-Individual-Schools/ (accessed May 2020).

19. Central Statistics Office (2012). This is Ireland, Highlights from Census 2011 Part 1, Dublin: The Stationary Office.

20. Harrington KE, McGowan MJ, Kiely M, et al. (2001). Macronutrient intakes and food sources in Irish adults: findings of the North/South Ireland Food Consumption Survey. Public Health Nutr 4(5a), 1051-60.

21. Holland B, Welch AA, Unwin ID, et al. (1995). McCance and Widdowson's The Composition of Foods. 5th ed. London: HSMO.

22. Food Standards Agency (2002). McCance and Widdowson's The Composition of Foods. Sixth summary edition. Cambridge: Royal Society of Chemistry.

23. Holland B, Unwin ID, Buss DH (1988). Cereal and Cereal Products. Third Supplement to McCance and Widdowson's The Composition of Foods. 4th ed. London: HSMO.

24. Holland B, Unwin ID, Buss DH (1989). Milk Products and Eggs. Fourth Supplement to McCance and Widdowson's The Composition of Foods. 4th ed. London: HSMO.

25. Holland B, Unwin ID, Buss DH (1991). Vegetables, Herbs and Spices. Fifth Supplement to McCance and Widdowson's The Composition of Foods. 4th ed. London: HSMO.

26. Holland B, Unwin ID, Buss DH (1992). Fruits and Nuts. First Supplement to McCance and Widdowson's The Composition of Foods. 5th ed. London: HSMO.

27. Holland B, Brown J, Buss DH (1993). Fish and Fish Products. Third Supplement to McCance and Widdowson's The Composition of Foods. 5th ed. London: HSMO.

28. Holland B, Welch AA, Buss DH (1996). Vegetable Dishes. Second Supplement to McCance and Widdowson's The Composition of Foods. 5th ed. London: HSMO. 
29. Chan W, Brown J, Buss DH (1994). Miscellaneous Foods. Fourth Supplement to McCance and Widdowson's The Composition of Foods. 5th ed. London: HSMO.

30. Chan W, Brown J, Lee SJ, et al. (1995). Meat, Poultry and Game. Fifth Supplement to McCance and Widdowson's The Composition of Foods. 5th ed. London: HSMO.

31. Chan W, Brown J, Church SM, et al. (1996). Meat Products and Dishes. Sixth Supplement to McCance and Widdowson's The Composition of Foods. 5th ed. London: HSMO.

32. Finglas P, Roe M, Pinchen $\mathrm{H}$, et al. (2015). McCance and Widdowson's The Composition of Foods. Seventh summary edition. Cambridge: Royal Society of Cambridge.

33. Leite JC, Hearty A, Nugent A, et al. (2010). A method for assessing dietary intakes of n-3 long-chain polyunsaturated fatty acids and trans fatty acids in an Irish adult population. Int $J$ Food Sci Nutr 61(6), 583-99.

34. United States Department of Agriculture (2019). USDA Food Composition Databases. https://ndb.nal.usda.gov/ndb/ (accessed May 2020).

35. National Institute for Health and Welfare (2019). Fineli Food Composition Database Version 20. https://fineli.fi/fineli/fi/index (accessed May 2020).

36. Food Institute Technical University of Denmark (2019). Food Data. https://frida.fooddata.dk/?lang=en (accessed May 2020).

37. Tooze JA, Kipnis V, Buckman DW, et al. (2010). A mixed-effects model approach for estimating the distribution of usual intake of nutrients: the NCI method. Statistics in Medicine 29(27), 2857-68.

38. Department of Health (1994). Nutritional aspects of cardiovascular disease. Report of the cardiovascular review group committee on medical aspects of food policy. London: HMSO.

39. Wearne SJ, Day MJ (1999). Clues for the development of food-based dietary guidelines: how are dietary targets being achieved by UK consumers? Br J Nutr 81(1), S119-S26.

40. Krebs-Smith S, Kott P, Guenther P (1989). Mean proportion and population proportion: two answers to the same question? J Am Diet Assoc 89(5), 671-6.

41. Li K, McNulty BA, Tiernery AM, et al. (2016). Dietary fat intakes in Irish adults in 2011: how much has changed in 10 years? Br J Nutr 115(10), 1798-809.

42. Pot GK, Prynne CJ, Roberts C, et al. (2012). National Diet and Nutrition Survey: fat and fatty acid intake from the first year of the rolling programme and comparison with previous surveys. Br J Nutr 107(3), 405-15.

43. Libuda L, Alexy U, Kersting M (2014). Time trends in dietary fat intake in a sample of German children and adolescents between 2000 and 2010: not quantity, but quality is the issue. $\mathrm{Br} J$ Nutr 111(1), 141-50.

44. Cui Z, Dibley MJ (2012). Trends in dietary energy, fat, carbohydrate and protein intake in Chinese children and adolescents from 1991 to 2009. Br J Nutr 108(7), 1292-9.

45. U.S. Department of Health and Human Services and U.S. Department of Agriculture (2015). Dietary Guidelines for Americans, 2015 - 2020.

https://health.gov/dietaryguidelines/2015/resources/2015-2020_Dietary_Guidelines.pdf (accessed May 2020).

46. Rippin HL, Hutchinson J, Jewell J, et al. (2019). Child and adolescent nutrient intakes from current national dietary surveys of European populations. Nutr Res Rev 32(1), 38-69. 
47. Reedy J, Krebs-Smith SM (2010). Dietary sources of energy, solid fats, and added sugars among children and adolescents in the United States. J Am Diet Assoc 110(10), 1477-84.

48. Vyncke KE, Libuda L, De Vriendt T, et al. (2012). Dietary fatty acid intake, its food sources and determinants in European adolescents: the HELENA (Healthy Lifestyle in Europe by Nutrition in Adolescence) Study. Br J Nutr 108(12), 2261-73.

49. Eilander A, Harika RK, Zock PL (2015). Intake and sources of dietary fatty acids in Europe: are current population intakes of fats aligned with dietary recommendations? Eur J Lipid Sci Technol 117(9), 1370-7.

50. Thorning TK, Tholstrup T, Astrup A, et al. (2017). Whole dairy matrix or single nutrients in assessment of health effects: current evidence and knowledge gaps. The American Journal of Clinical Nutrition 105(5), 1033-45.

51. Sioen I, Huybrechts I, Verbeke W, et al. (2007). n-6 and n-3 PUFA intakes of pre-school children in Flanders, Belgium. Br J Nutr 98(4), 819-25.

52. Sichert-Hellert W, Wicher M, Kersting M (2009). Age and time trends in fish consumption pattern of children and adolescents, and consequences for the intake of long-chain n-3 polyunsaturated fatty acids. Eur J Clin Nutr 63(9), 1071.

53. Guesnet $\mathrm{P}$, Tressou J, Buaud B, et al. (2019). Inadequate daily intakes of n-3 polyunsaturated fatty acids (PUFA) in the general French population of children (3-10 years) and adolescents (11-17 years): the INCA2 survey. Eur J Nutr 58(2), 895-903.

54. Uauy R, Dangour AD (2006). Nutrition in brain development and aging: role of essential fatty acids. Nutr Rev 64(2), S24-S33.

55. Guesnet P, Alessandri J-M (2011). Docosahexaenoic acid (DHA) and the developing central nervous system (CNS)-implications for dietary recommendations. Biochimie 93(1), 7-12.

56. Rahmawaty S, Charlton K, Lyons-Wall P, et al. (2013). Dietary intake and food sources of EPA, DPA and DHA in Australian children. Lipids 48(9), 869-77.

57. Australian Bureau of Statistics (2014). Australian Health Survey : Nutrition First Results Food and Nutrients. ABS.

https://www.ausstats.abs.gov.au/Ausstats/subscriber.nsf/0/4683FD7315DFDFDBCA257D080014F 9E0/\$File/australian\%20health\%20survey\%20nutrition\%20first\%20results\%20\%20food\%20and\%20nutrients,\%202011-12.pdf (accessed May 2020).

58. Kranz S, Jones N, Monsivais P (2017). Intake levels of fish in the UK paediatric population. Nutrients 9(4), 392. 